\title{
Health Systems in East Asia: What Can Developing Countries Learn from Japan and the Asian Tigers?
}

\author{
by \\ Adam Wagstaff \\ The World Bank, Washington DC, USA
}

\begin{abstract}
Summary
The health systems of Japan and the Asian Tigers (Hong Kong (China), the Republic of Korea, Singapore and Taiwan (China)), and the recent reforms to them, provide many potentially valuable lessons to East Asia's developing countries. All five systems have managed to keep a check on health spending despite their different approaches to financing and delivery. These differences are reflected in the progressivity of health finance, but the precise degree of progressivity of individual sources and the extent to which households are vulnerable to catastrophic health payments depend too on the design features of the system-the height of any ceilings on social insurance contributions, the fraction of health spending covered by the benefit package, the extent to which the poor face reduced copayments, whether there are caps on copayments, and so on. On the delivery side, too, Japan and the Tigers offer some interesting lessons. Singapore's experience with corporatizing public hospitals-rapid cost and price inflation, a race for the best technology, and so on-illustrates the difficulties of corporatization. Korea's experience with a narrow benefit package illustrates the danger of providers shifting demand from insured services with regulated prices to uninsured services with unregulated prices. Japan, in its approach to rate-setting for insured services, has managed to combine careful cost control with fine-tuning of profit margins on different types of care. Experiences with diagnosis-related groups in Korea and Taiwan (China) point to cost-savings but also to possible knock-on effects on service volume and total health spending. Korea and Taiwan (China) both offer important lessons for the separation of prescribing and dispensing, including the risks of compensation costs outweighing the cost savings caused by more 'rational' prescribing, and cost-savings never being realized because of other concessions to providers, such as allowing them to have onsite pharmacists.
\end{abstract}

Corresponding author and contact details: Adam Wagstaff, The World Bank, $1818 \mathrm{H}$ Street NW, Washington, D.C. 20433, USA. Tel. (202) 473-0566. Fax (202)-522 1153. Email: awagstaff@worldbank.org.

Keywords: Health systems; Kong Kong; Japan; Korea; Taiwan; Singapore.

World Bank Policy Research Working Paper 3790, December 2005

The Policy Research Working Paper Series disseminates the findings of work in progress to encourage the exchange of ideas about development issues. An objective of the series is to get the findings out quickly, even if the presentations are less than fully polished. The papers carry the names of the authors and should be cited accordingly. The findings, interpretations, and conclusions expressed in this paper are entirely those of the authors. They do not necessarily represent the view of the World Bank, its Executive Directors, or the countries they represent. Policy Research Working Papers are available online at http://econ.worldbank.org.

Acknowledgements: My thanks to Soonman Kwon and Gabriel Leung for help in locating resources, and for sharing with me their unpublished manuscripts. 


\section{INTRODUCTION}

Developing countries - understandably — often show more interest in learning from the health systems of industrialized economies, rather than from one another's. For the developing countries of East Asia, one especially relevant group of industrialized economies are Japan and the Asian Tigers (Hong Kong (China), the Republic of Korea, Singapore and Taiwan (China)). It is true that even countries such as China, Malaysia and Thailand (the richer developing countries in East Asia) lag far behind Japan and the Tigers in terms of per capita income, and that on present trends they may well never catch up (Figure 1). ${ }^{*}$ But in terms of health system challenges and solutions, the gaps are smaller than per capita income gaps suggest-both within the Japan-Tiger grouping, and between the Japan-Tiger grouping and the developing countries of East Asia.

Figure 1: Per capita incomes in selected East Asian economies, 1960-2003 ${ }^{\dagger}$

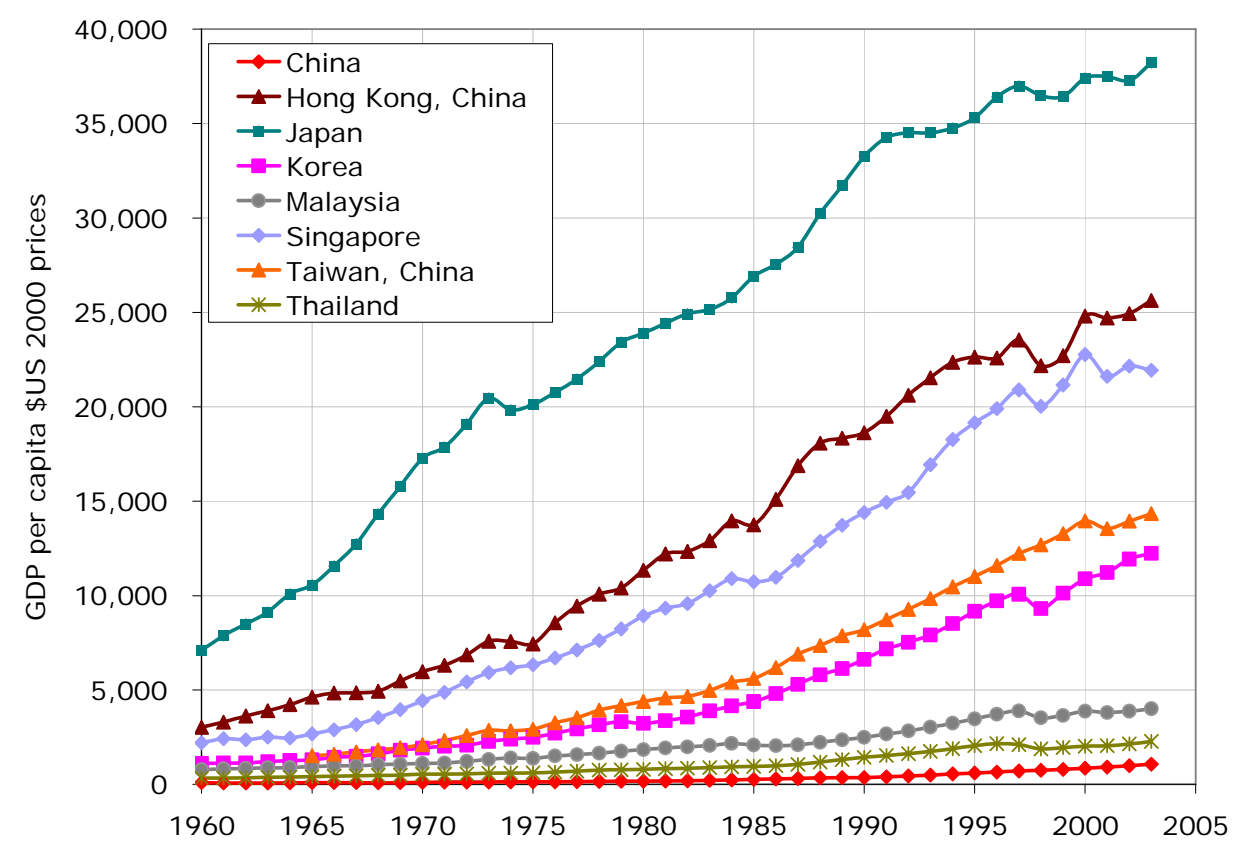

All health systems face the problem of how to pay providers. Japan, richer than the Tigers, has been most successful in devising a non-inflationary and non-distortionary fee schedule, but it is Korea and Taiwan (China) that are ahead in introducing prospective payment methods. Policymakers in many systems are conscious of the pitfalls of the shared approach (a legacy of Chinese medicine) of having the same person both prescribe and dispense medicines.

\footnotetext{
* In terms of GDP per capita, China today is roughly where Korea and Taiwan (China) were in 1960. Malaysia today is roughly where Taiwan (China) was in 1997, and Korea was in 1984. And Thailand today is roughly where Korea and Taiwan (China) were in the early 1970s.

${ }^{\dagger}$ Data are from the World Bank’s World Development Indicators. GDP per capita is at constant 2000 prices, expressed in US dollars, not purchasing power parities (PPP) due to the shorter time-series for PPP GDP per capita data.
} 
But again it is Korea and Taiwan (China) that are making the fastest progress on the issue. Most systems in the region have opted for some form of universal coverage, or aspire to achieve it. Korea introduced universal health insurance (UHI) in 1989, six years ahead of Taiwan (China) despite being poorer than Taiwan (China), and despite being poorer than Japan was when it introduced UHI (1961). China, The Philippines, Thailand and Vietnam are all currently taking major steps towards universal coverage, and on present trends look set to achieve it well before they reach even the per capita income Korea had when it did so.

In short, despite the wide income differences within the Japan-Tiger grouping and between that grouping and the developing economies of East Asia, the opportunities for lessonlearning in the health sector would seem to be considerable. This paper provides an analytical overview of the health systems of Japan and the Asian Tigers, and suggests some lessons for the developing countries of the region. The focus is not on describing the five systems, but rather on linking their policies and institutional arrangements to outcomes of interest, such as health spending, unit costs, and use of services. The paper tries to pull out lessons both from looking across the systems, and from looking at the impacts of reforms within the various systems. Over the last few years, the availability of quality comparable data across the systems has improved. The efforts by $\mathrm{OECD}^{1}$ and $\mathrm{WHO}^{2}$ on health spending and sources of financing have helped improved comparability of data for Japan, Korea and Singapore, and Hong Kong (China) ${ }^{*}$ and Taiwan (China) ${ }^{3}$ have complemented this work with their own health accounts. And four of the five systems-Singapore is the exception-have also been represented in a multi-system Asian comparative study on equity in health care finance and delivery, known as the Equitap project. ${ }^{\dagger}$ In addition, the last few years have seen several interesting policy reforms in the systems, some of which have been the subject of careful evaluation. These evaluations, as well as the data emerging from the health accounts and Equitap project, constitute the evidence base for this paper.

The paper begins in section II with the financing of health care, comparing the shares of GDP spent by the different systems on health care, and the revenue sources used in the financing of it. Also reviewed is evidence on the progressivity of health financing in the different systems, and the extent to which households-especially poor ones-are protected from catastrophic health expenses. The results are interpreted in the light of schemes aimed at cushioning the poor from copayments. The paper then turns in section III to the delivery and use of health services, reviewing the roles of the public and private sectors, and the ways providers are paid and their influence on provider organization. Also reviewed are recent reforms concerning provider payments, and the separation of drug prescribing and dispensing. The paper reviews in the light of this the evidence on utilization rates, comparing rates to OECD averages, and the extent of inequalities across income groups in use of different types of services. The final section-section IV-contains the conclusions.

\footnotetext{
*Hong Kong (China)’s ‘domestic’ health accounts are available at http://www.hwfb.gov.hk/statistics/en/dha.htm.

† The project's homepage is at http://www.equitap.org/.
} 


\section{HEALTH CARE FINANCE}

How much do Japan and the Tigers spend on health care? How do they finance their spending? Who bears the financing burden? Do the poor pay proportionately more or less for their health care than the better off? And how far are people protected from catastrophic health payments? These are the questions addressed in this section.

\section{How much is spent on health care?}

Across health systems, it is well known that the share of GDP devoted to health tends to rise with GDP per capita. Japan-a good deal richer than the richest Tiger economy (Hong Kong (China)) - actually spends somewhat more than is predicted from a cross-section regression of total health expenditure (as a share of GDP) on per capita income (Figure 2). The Tigers, by contrast, spend less than predicted by the regression, the biggest 'under-spender' by a long way being Singapore, whose share of GDP devoted to health is barely half the predicted figure. (The other three Tigers all spend $80-90 \%$ of their 'expected' shares.)

Figure 2: Health spending and GDP*

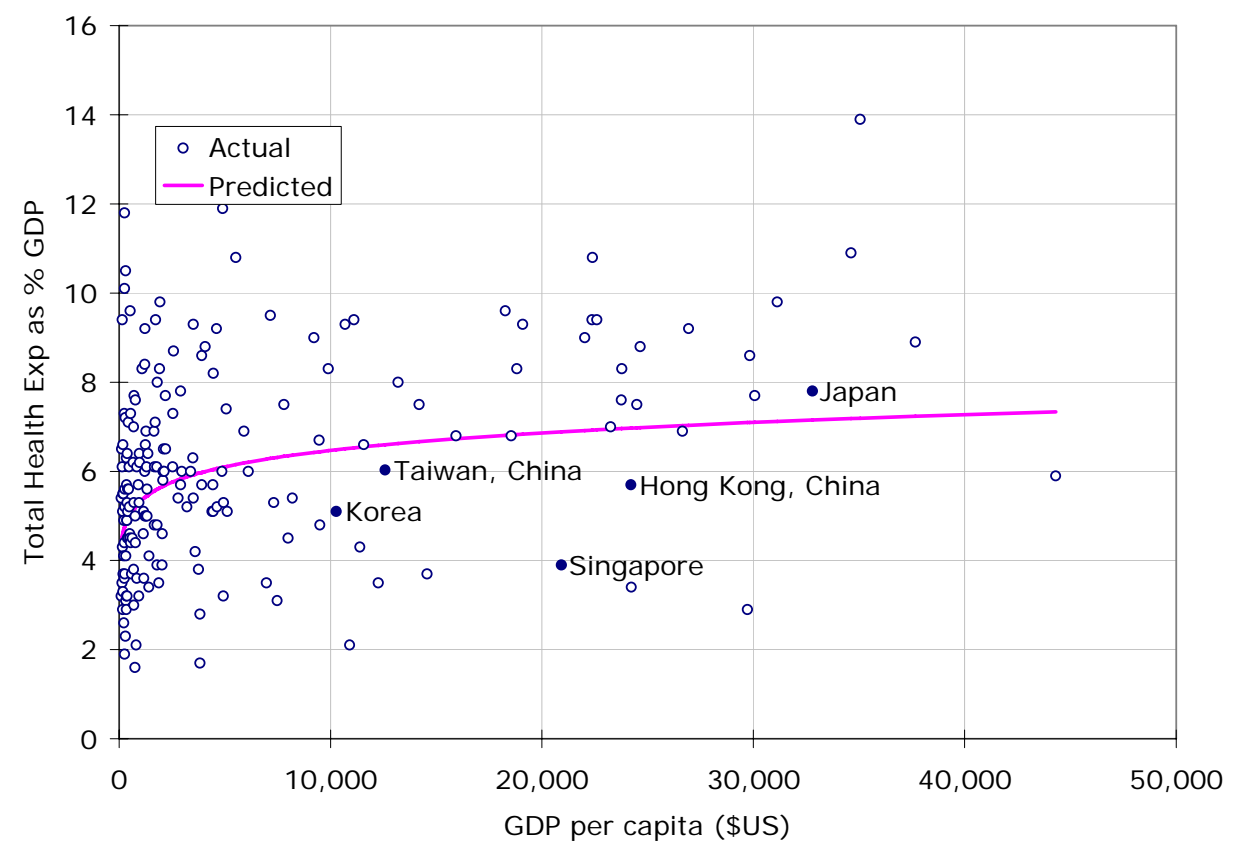

\footnotetext{
* Data refer to 2001 the latest year for which complete data are available. The predicted figures are from a regression of the natural logarithm of total health expenditure (expressed as a share of GDP) on the natural logarithm of GDP per capita. Data are from the 2005 World Health Report annexes in the cases of Japan, Korea and Singapore. The per capita income data for Hong Kong (China) and Taiwan (China) are from the World Bank’s World Development Indicators. Data on health spending are from http://www.hwfb.gov.hk/statistics/download/dha/en/table1.pdf in the case of Hong Kong (China) and from http://www.doh.gov.tw/ufile/doc/200411_Statistic\%20of\%20Expenditure\%20for\%20Health,\%201991-2003.pdf in the case of Taiwan (China).
} 
Between 1998 and 2001, all four economies increased their share of GDP devoted to health, with Hong Kong (China) increasing its share most slowly and Taiwan (China) most quickly (Table 1). Over the same period, Singapore's share fell further below its expected share, but the other Tigers all moved closer towards their expected share, Taiwan (China) most quickly. It was over this period that Japan moved from being on the regression line to above it. In sum, while the degree to which the Tigers 'under-spend' on health care has-with the exception of Singapore-diminished somewhat recently, this trend would have to continue much longer before one could begin to question the ability of these systems to keep aggregate spending under control.

Table 1: Changes in actual and predicted share of GDP spent on health, 1998-2001*

\begin{tabular}{lccccccc}
\hline & \multicolumn{5}{c}{ Share of GDP spent on health } & \multicolumn{2}{c}{ Actual share as percentage of predicted share } \\
\hline & 1998 & 2001 & $\begin{array}{c}\text { Percentage } \\
\text { point } \\
\text { change p.a. }\end{array}$ & $\begin{array}{c}\text { Percentage } \\
\text { change p.a. }\end{array}$ & 1998 & 2001 & \% change \\
\hline Hong Kong (China) & 5.6 & 5.7 & 0.02 & $1 \%$ & $78 \%$ & $82 \%$ & $4 \%$ \\
Japan & 7.2 & 7.8 & 0.12 & $3 \%$ & $99 \%$ & $109 \%$ & $11 \%$ \\
Korea & 4.3 & 5.1 & 0.16 & $6 \%$ & $68 \%$ & $79 \%$ & $16 \%$ \\
Singapore & 4.2 & 3.9 & -0.06 & $-2 \%$ & $60 \%$ & $57 \%$ & $-5 \%$ \\
Taiwan (China) & 5.5 & 6.0 & 0.11 & $3 \%$ & $82 \%$ & $91 \%$ & $12 \%$ \\
\hline
\end{tabular}

\section{How is health spending financed?}

The five health systems vary in how they raise the revenues used to finance health care (Figure 3). At one extreme is Hong Kong (China), which finances just over half of its health spending through general tax and non-tax revenues. At the other extreme is Singapore, which finances as much as two thirds of its health spending through out-of-pocket payments. In the middle are Japan, Korea and Taiwan (China), all of which rely on social insurance for half (or nearly half in the case of Korea) of their health spending. Noteworthy is the fact that out-ofpocket payments account for over $30 \%$ of health expenditures in all systems, with the exception of Japan, and that private insurance accounts for a fairly small share in Hong Kong (China) and Taiwan (China), and a negligible share in the other three systems.

\footnotetext{
* The predicted figures are from the same regression as used in Figure 2. Data for 1998 are from the same sources as in Figure 2.
} 
Figure 3: Health financing mixes in Japan and the Asian Tigers*

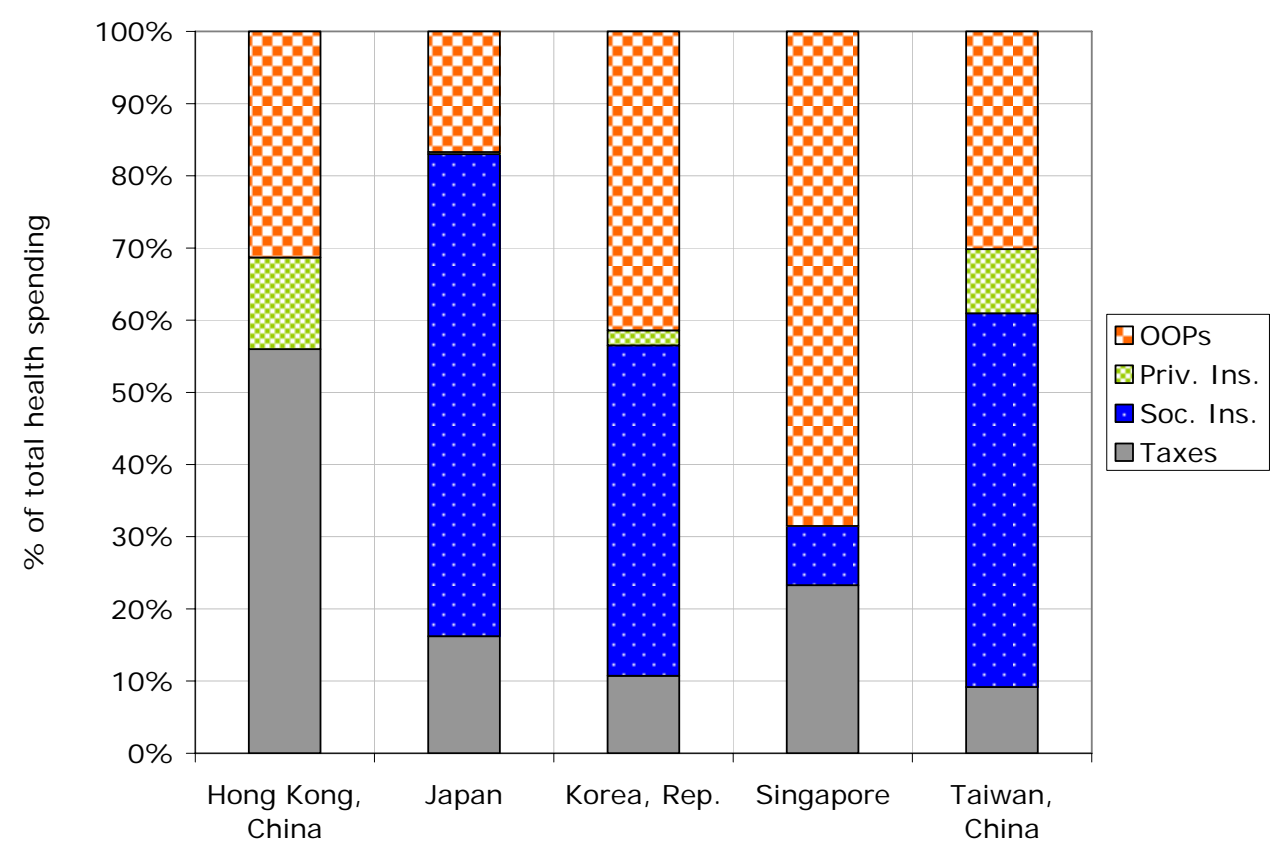

Figure 4 shows the evolution of the out-of-pocket share from 1960 onwards, as well as the dates where key reforms occurred, notably the introduction of universal health insurance (UHI) in Japan (1961), Korea (1989) and Taiwan (China) (1995), and the introduction of medical savings accounts (MSAs) in Singapore (1984). The high pre-UHI out-of-pocket shares in Japan, Korea and Taiwan (China) reflected in part the uncovered sections of the population, but also the services that existing plans left uncovered. For example, in Taiwan (China) prior to UHI, 43\% of the population was uncovered, because existing schemes did not cover dependents of formal sector workers, the elderly, the disabled and the young. ${ }^{5}$ In Korea, many services were-and continue to be- uncovered by health insurance plans, for which patients pay out-of-pocket. ${ }^{6}$

The out-of-pocket share dropped markedly following the introduction of UHI in Korea and Taiwan (China), and after a lag started falling in Japan too. By contrast, the introduction of MSAs in Singapore appears to have had little effect on the out-of-pocket share there. Indeed, in contrast to the systems that went down the UHI route, which have all seen downwards trends in the out-of-pocket share rather than simply one-off reductions, Singapore's out-of-pocket share has, if anything, drifted upwards since MSAs were introduced. MSAs themselves have consistently accounted for only $8-10 \%$ of total health spending in Singapore. ${ }^{7-9}$ This stems from the fact that they are mainly for inpatient spending, and there is an upper limit on the amount that can be withdrawn per day. ${ }^{10}$ Singapore's two complementary schemes, Medishield (a low-cost catastrophic illness insurance scheme, introduced in 1990) and Medifund (a means-tested public safety net of last resort for the poor, introduced in 1993), have absorbed even smaller shares, currently less than $2 \%$ combined. $^{9}$

\footnotetext{
* Data are from the 2005 World Health Report in the cases of Japan, Korea and Singapore, and refer to 2003. For Hong Kong (China) and Taiwan (China), they are from O'Donnell et al. ${ }^{4}$
} 
Figure 4: Trends in the out-of-pocket share in Japan and the Asian Tigers*

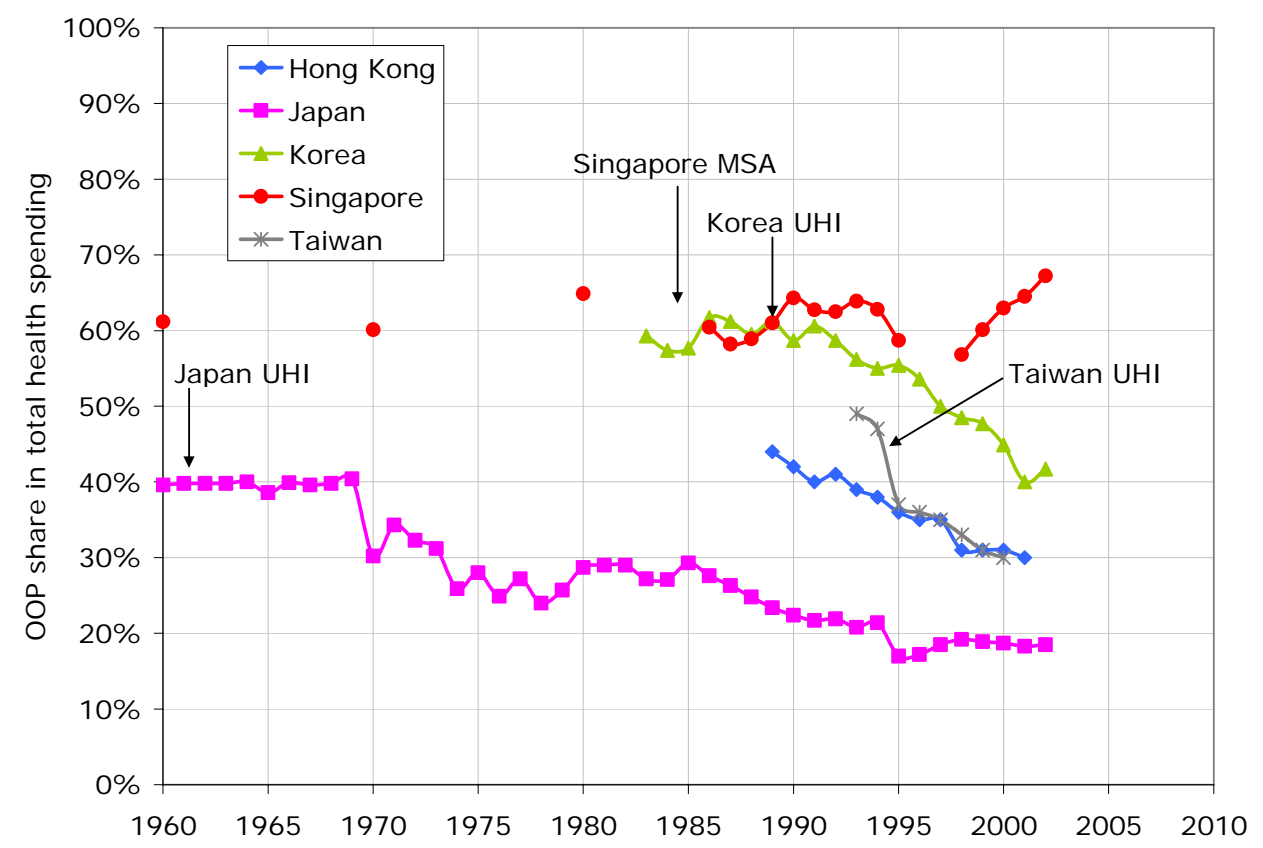

\section{Who bears the burden of health finance?}

How is the burden of health finance distributed across income groups? Figure 5 shows the progressivity of the various finance sources as well as of total payments for four of the five systems. ${ }^{\dagger}$ Only in Hong Kong (China) are total payments progressive. They are most regressive in the case of Japan, but the differences with Korea and Taiwan (China) are not marked.

\footnotetext{
* Data for Hong Kong (China) are from http://www.hwfb.gov.hk/statistics/download/dha/en/table2.pdf. Data for Japan and Korea are from OECD Health Statistics. Data for Singapore are from Liu and Yue ${ }^{7}$ for 1960-95, and from the 2005 World Development Report for 1998-2002. Data for Taiwan (China) are from Lu ${ }^{11}$. UHI denotes universal health insurance. MSAs denote medical savings accounts.

${ }^{\dagger}$ Distributional data of the type in the next two charts are not available for Singapore, which is a pity given its uniqueness and the often strong claims that are made for its success.
} 
Figure 5: Progressivity of health financing sources in Japan and the Asian Tigers*

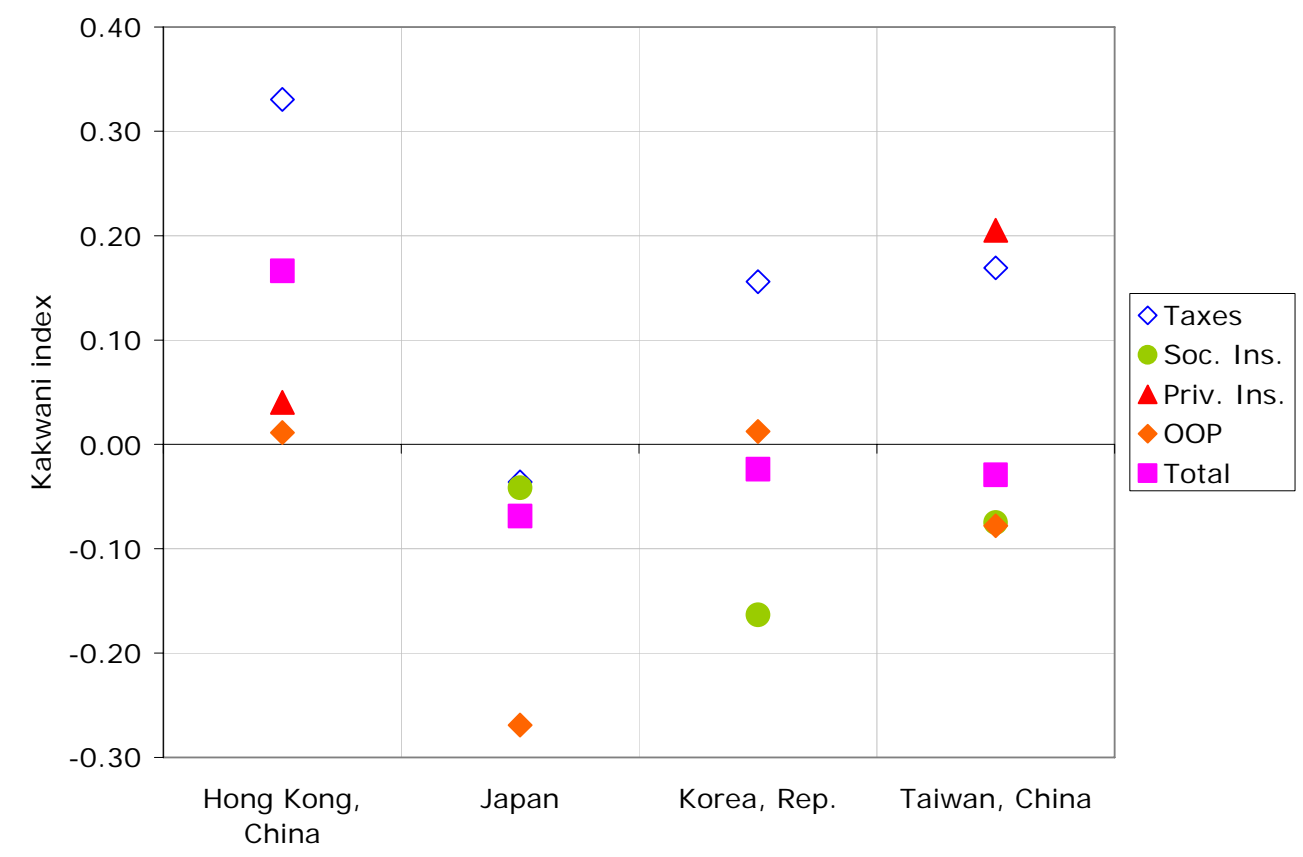

The differences in the progressivity of total payments reflect the different shares raised from the various sources (Figure 3 ) and the progressivity of each source (Figure 5). ${ }^{\dagger}$ Taxes are most progressive in Hong Kong (China), which is also the health system that relies most on them in the financing of health care. They are regressive in Japan (largely because of the regressiveness of indirect taxes there ${ }^{4}$ ), but progressive-albeit less so than in Kong Hong (China) - in Korea and Taiwan (China).

Social insurance contributions are regressive in all systems where they are used. This is not unusual and typically reflects the effects of contributions ceilings. ${ }^{13,14}$ Any exemptions or reduced contribution rates among the poor would reduce the degree of regressiveness, and could in principle make contributions progressive. In Korea ${ }^{15}$ and Taiwan (China) ${ }^{11}$ there are exemptions or reduced contribution rates for the poor or otherwise disadvantaged (in the case of Taiwan (China) the poorest $1 \%$ of households are fully exempt, and a further $4.5 \%$ have their contributions paid in full or subsidized). In Japan, contributions emerge as proportional despite the fact that different insurance plans (there are over 5000 plans under the UHI umbrella) have different contribution rates. ${ }^{16-18}$

The progressiveness of private insurance — especially so in Taiwan (China)—reflects the fact that it is the better off who buy it. In both Hong Kong (China) and Taiwan (China), private insurance buys supplementary cover. Out-of-pocket payments emerge as proportional in Hong Kong (China) and Korea, mildly regressive in Taiwan (China), and regressive in Japan. The

\footnotetext{
* A positive value of Kakwani's ${ }^{12}$ index indicates a progressive payment structure, a zero value proportional payments, and a negative value a regressive structure. The data shown are from O’Donnell et al. ${ }^{4}$

${ }^{\dagger}$ The Kakwani indices for total payments are a weighted average of the Kakwani indices for the individual payments sources where the weights are the revenues shares.
} 
progressivity (or regressiveness) of out-of-pocket payments reflects in part the fraction of health services covered by the benefit package, and in part the extensiveness of exemptions and reduced copayments for insured services, and the degree to which these are linked to income. If all services are covered by insurance, and everyone is liable to the same copayments, out-of-pocket payments will inevitably emerge as regressive. If, on the other hand, the benefit package is fairly narrow, and the better off are those paying for the uncovered services, out-of-pocket payments are likely to emerge as progressive. This will be offset-at least in part-by any linking of copayments to income for the insured services. Korea is an example of the second situation. The UHI benefit package is narrow, and half of all out-of-pocket payments are for uncovered services. ${ }^{19}$ However, UHI exempts people on Medical Aid from copayments on covered services, and there are reduced copayments for the elderly, patients requiring long-term care for catastrophic and/or chronic conditions. Japan and Taiwan (China), by contrast, have nearcomprehensive benefit packages, and in Japan's case, extra-billing (charging patients extra on top of the insurer's fee schedule) is strictly prohibited, except for nine well defined areas. $5,11,16-18$ Taiwan (China) — in contrast to Japan-exempts very poor households from cost-sharing.,

These progressivity results do not shed light on the question of horizontal inequities in the finance of health care. ${ }^{20}$ For example, a major issue in all three social insurance systems has been the different contribution rates across insurance plans. In Korea over the period 1989-2000, 350 separate insurance plans coexisted under the UHI umbrella. In Japan, even now over 40 years after the introduction of UHI, more than 5000 plans coexist under the UHI umbrella. All offer the same benefits, but their contribution bases and risks vary. In both countries, the equalization funds managed to reduce but did not eliminate the effects of these differences. The result was that prior to the merging of funds in Korea in 2000 and in Japan even today, different insurance schemes had (and continue to have in Japan's case) different contribution rates. ${ }^{15,18}$

\section{Are households protected from catastrophic spending?}

Also of interest-especially for out-of-pocket payments which are unpredictable and potentially large - is the extent to which payments for health care turn out to be catastrophic, in the sense they absorb an unduly large share of income or household spending. ${ }^{21,22}$ In addition to being interested in the fraction of the population incurring catastrophic out-of-pocket expenses, one might want to know the extent to which catastrophic payments are concentrated among the poor. $^{21}$

Figure 6 shows the incidence of catastrophic payments for different thresholds (annualized per capita payments exceeding 5\%, 10, 15\% and 25\% of total annual per capita household spending), as well as the extent to which catastrophic payments are concentrated among the poor (a negative concentration index) or among the better off (a positive concentration index). Whatever the threshold, Korea emerges as having a higher incidence of catastrophic out-of-pocket payments than Hong Kong (China) and Taiwan (China). For a threshold of $10 \%$ and higher, Hong Kong (China) and Taiwan (China) have similar fractions of people recording catastrophic out-of-pocket expenses. However, what sets Taiwan (China) apart is that as the threshold is raised, catastrophic payments become more and more concentrated among the poor, whereas the opposite is true in Hong Kong (China) and Korea. This is despite the fact that in Taiwan (China)—as in Japan and Korea-out-of-pocket payments for insured 
services are capped.,11,16-19 The reason why in Taiwan (China) catastrophic payments become increasingly concentrated among the poor as the threshold is raised but do not in Korea is likely to be due to the fact that Korea's benefit package is so limited and that of Taiwan (China) so broad. Those incurring especially large out-of-pocket payments in Korea are likely to be people whose out-of-pocket spending reflects at least in part payments for uncovered services, the demand for which is likely to rise strongly with income. In Taiwan (China), by contrast, they are likely to be people incurring large copayments for covered services, and the demand for these, it seems, is not higher among the better off (more on this below).

Figure 6: Catastrophic out-of-pocket payments in Japan and the Asian Tigers*

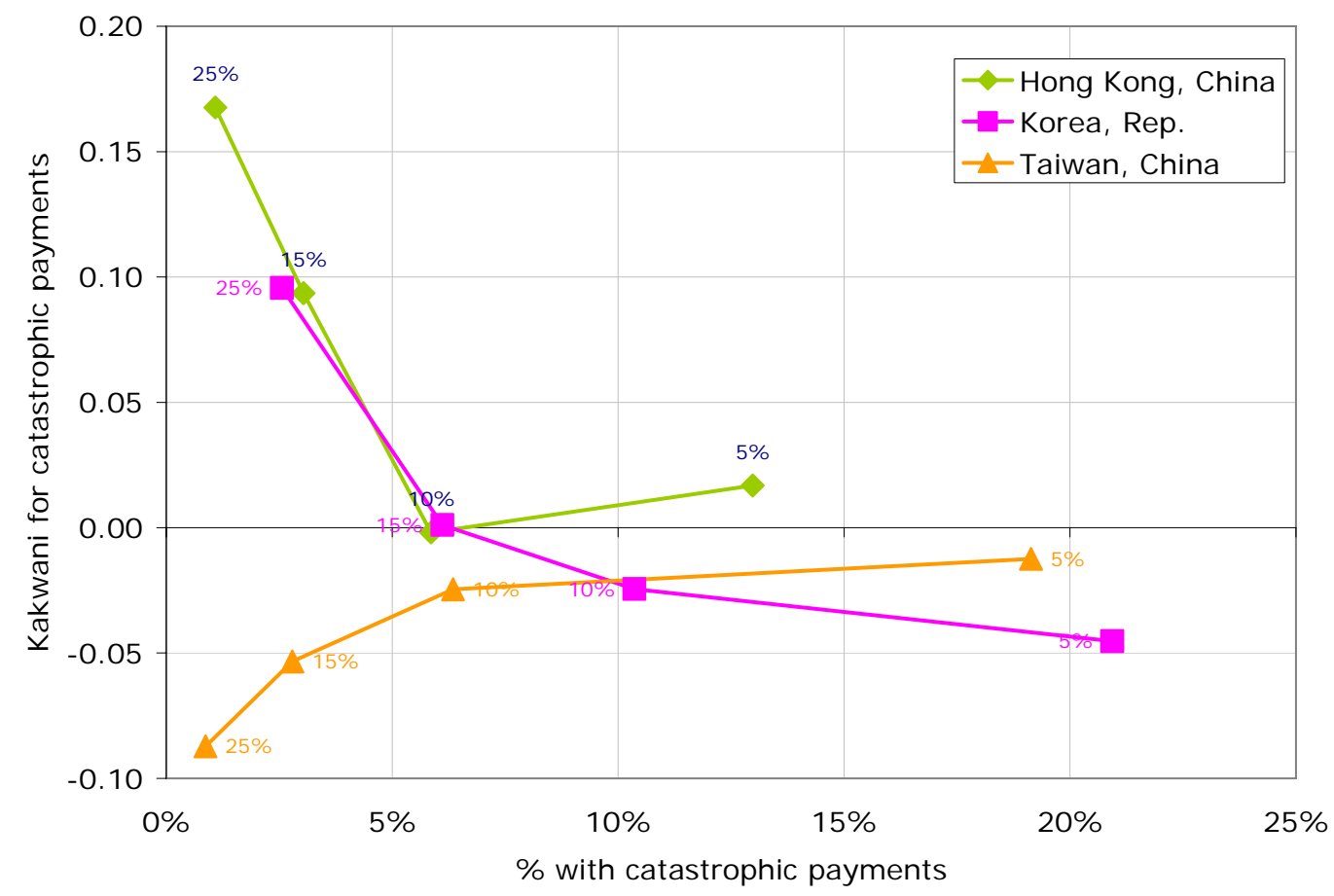

The introduction of UHI in Japan, Korea and Taiwan (China) all led (albeit after a lag in the case of Japan) to a reduced emphasis on out-of-pocket payments. It is plausible that exposure to the risk of very large out-of-pocket payments also fell. If this is the case, households affected by UHI can be expected to have reduced precautionary savings. In the case of Taiwan (China), this appears to have happened-estimates derived by comparing before-and-after changes in saving behavior of those gaining insurance as the result of UHI suggest that the introduction of UHI reduced savings in Taiwan (China) by $9-14 \%{ }^{24}$ The largest proportionate impacts were observed for those saving least before the reform.

\footnotetext{
* The figure shows the fraction of households with annualized per capita out-of-pocket payments exceeding 5\%, 10\%, 15\% and $25 \%$ of annual per capita total household spending. Also shown is the concentration index for the incidence of catastrophic payments. A positive index indicates catastrophic payments were more common among the better off, while a negative index indicates they were more common among the poor. The data shown in Figure 3 are from van Doorslaer et al. ${ }^{23}$
} 


\section{HEALTH CARE DELIVERY AND UTILIZATION}

How is the delivery of health care organized? What role do the public and private sectors play, and how far are first- and second-level providers differentiated from one another? How are providers paid, and how does this influence the organization and delivery of care? What reforms have there been to provider payments and provider organization, and with what results? Who uses health care and how much? These are the questions considered in this section.

\section{Ownership and provider payments}

Ambulatory care in the five systems is provided largely by the private sector (Table 2). Differences emerge, however, in the hospital sector: the hospital sectors of Hong Kong (China) and Singapore are both largely public, while in the three social insurance systems-Japan, Korea and Taiwan (China)-hospitals are largely private. In terms of the private-public mix, then, the five systems span all four possible combinations or ownership and finance. The first-level clinics in Hong Kong (China) and Singapore are mainly privately owned and operated, and are mainly privately financed, mostly out-of-pocket. The ambulatory care clinics in Japan, Korea and Taiwan (China), like the hospitals in these three systems, are also largely privately operated, but receive large amounts of public finance through UHI reimbursement. The hospital sector in Hong Kong (China) is largely publicly owned and operated, but is financed largely (80\%) out of general revenues.* By contrast, the hospital sector in Singapore, which is also still largely publicly owned and operated (more on this below), relies heavily (though increasingly less so ${ }^{25}$ ) on private finance. ${ }^{\dagger}$

Table 2: Percentage of consultations, admissions, physicians and facilities in public sector ${ }^{\ddagger}$

\begin{tabular}{|c|c|c|c|c|c|c|c|}
\hline & $\begin{array}{c}\text { Doctors } \\
\text { per } 10,000 \\
\text { persons }\end{array}$ & $\begin{array}{c}\text { Beds per } \\
10,000 \\
\text { persons }\end{array}$ & $\begin{array}{c}\text { Ambulatory } \\
\text { consultations } \\
\% \text { public }\end{array}$ & $\begin{array}{c}\text { First-level } \\
\text { physicians } \\
\% \text { public }\end{array}$ & $\begin{array}{c}\text { Hospital } \\
\text { admissions } \\
\% \text { public }\end{array}$ & $\begin{array}{l}\text { Hospital } \\
\text { beds \% } \\
\text { public }\end{array}$ & $\begin{array}{l}\text { Hospit } \\
\text { als \% } \\
\text { public }\end{array}$ \\
\hline \multicolumn{8}{|l|}{ Hong Kong } \\
\hline (China), China & 15.8 & 52 & $28 \%$ & $45 \%$ & $82 \%$ & $86 \%$ & $76 \%$ \\
\hline Japan & 20.2 & 129 & & $36 \%$ & & $33 \%$ & $20 \%$ \\
\hline Korea, Rep. & 19.4 & 66 & & $10 \%$ & & $10 \%$ & $10 \%$ \\
\hline Singapore & 15.0 & 28 & $20 \%$ & & $74 \%$ & $81 \%$ & \\
\hline \multicolumn{8}{|l|}{ Taiwan (China), } \\
\hline China & 14.0 & 59 & & $3 \%$ & & $32 \%$ & $15 \%$ \\
\hline OECD average & 28.0 & 60 & & & & & \\
\hline
\end{tabular}

The five systems all share a common feature, namely that their ambulatory facilities offer a wider range of services than a typical ambulatory facility in the West. In Singapore, for example, ambulatory clinics offer X-rays, clinical laboratory tests, and some rehabilitative services. ${ }^{27}$ In Japan, many physician offices (one third of the total) even have a few outpatient beds. $^{17}$ And in Japan, as in Hong Kong (China) ${ }^{28}$, clinics offer specialist care, not just primary

\footnotetext{
* See Hong Kong (China)’s ‘domestic’ health accounts at http://www.hwfb.gov.hk/statistics/en/dha.htm.

${ }^{\dagger}$ No national health accounts are available for Singapore ${ }^{2 \overline{6}}$, and I have been unable to establish the share of hospital costs borne by the taxpayer.

${ }^{\ddagger}$ Data on doctors and beds from WHO http://www.wpro.who.int/information_sources/databases/core_indicators/, except Taiwan (China) where the numbers are from Taiwan (China)'s statistical yearbook

http://ecommerce.taipeitimes.com/yearbook2004/P243.htm and the OECD averages which are from OECD Health Data ${ }^{1}$.
} 
care-indeed, the notion of primary care in these systems is not one of general practice or family medicine. ${ }^{28}$ At least until recently, many clinics also prescribe and dispense drugs (see below).

In part, the expanded scope of first-level clinics compared to Western clinics reflects financial incentives. Fist-level clinics are paid fee-for-service (FFS) in all five systems, whether directly by patients in the cases of Hong Kong (China) and Singapore, or by insurers (and sometimes patients themselves) in the cases of Japan, Korea and Taiwan (China). In Hong Kong (China) and Singapore, the fees are largely unregulated, and there is clearly scope for clinics to offer services that might elsewhere be provided in a hospital setting. In Japan, where payments are by the insurer (extra-billing is prohibited), first-level providers and hospitals have traditionally been paid FFS. Moreover, the fee schedule is the same for physician offices and hospitals, and the range of services first-level providers can claim reimbursement for is apparently largely unrestricted. ${ }^{17}$ This is reinforced by the fact that physicians working at the first level have no hospital admission rights, and as a result rarely refer patients to hospital. The result is a markedly undifferentiated delivery system, where the distinctions between the first and second levels are increasingly blurred. First-level clinics end up offering services typically associated with a hospital, and hospitals end up setting up large outpatient clinics. In Korea, the story is much the same-an undifferentiated structure caused by a common fee schedule for firstand second-level facilities, and first-level providers having no hospital admission rights. ${ }^{6}$ These two contributory factors in Korea's case are reinforced by the fact that, in contrast to Japan, the benefit package in Korea is fairly limited (half of all out-of-pocket payments are payments in full for uncovered services ${ }^{19}$ ) and clinics and hospitals compete with one another in a lucrative and unregulated market for medical services left uncovered by UHI. It is speculated that providers exploit the information asymmetry in the health care market and try to shift demand from covered services whose prices are regulated to uncovered services whose prices are determined entirely by the market. ${ }^{19}$ In Taiwan (China), in contrast to Japan and Korea, the fee schedule is differentiated between different types of facilities, and indeed within the hospital sector a more generous fee schedule applies to better-equipped hospitals. This, unsurprisingly, has resulted in hospitals upgrading themselves in order to achieve higher status in the accreditation process. ${ }^{11}$

The setting of fees for covered services has a potentially large impact on which type of services end up being delivered to whom, through their influence on patients' willingness and ability to pay for different types of service, and on the profit margins providers can earn on them. In China, through a well-intentioned policy of underpicing ambulatory and basic hospital care and overpricing high-tech hospital care and drugs, the authorities inadvertently ended up encouraging providers to shift demand to the latter and to under-provide the former. ${ }^{29}$ In Korea a similar problem has been noted. ${ }^{19}$ Korea has a Caesarian section rate of $43 \%$, compared to Japan's $15 \%$ and the United Kingdom's $20 \% .{ }^{6}$ Korea also has a stronger demand for residency training in specialties with generous margins such as ophthalmology and dermatology. ${ }^{19}$ Japan, by contrast, has evolved a highly successful fee schedule. ${ }^{17}$ The authorities undertake a biennual review of each of more than 3000 items, rather than making across-the-board proportionate changes in all. They selectively reduce the fees of procedures that show "inappropriate" volume expansion. They deliberately price high-tech care below cost and basic ambulatory care above cost - the exact opposite of China's current practice. They keep a tight control on fee increases, and increasingly bundle items together. The results have been interesting. Fees for lab tests and diagnostic imaging in Japan have fallen over the years. Despite the fact that high-tech care is unprofitable in Japan, hospitals nonetheless do deliver it, perhaps because they feel that a 
reputation for delivery of high-tech care helps attract all types of patients, and perhaps because doctors find the delivery of high-tech care professionally rewarding. ${ }^{17}$ Japan's fee schedule is often argued to be one of the reasons it has been able to keep health spending checked despite 40 years of UHI and FFS. ${ }^{17}$

Of course, FFS is far from ideal, and unsurprisingly shifts away from FFS have started in all three social insurance systems. In 1993, Japan introduced an all-inclusive per diem reimbursement rate for its geriatric hospitals which bundled drugs, lab tests, etc. together. Costs of medications fell by one third, and the costs of lab tests fell to one tenth of their previous level. ${ }^{17,18}$ In 1998, Japan piloted a DRGs in 10 hospitals with 183 DRGs, and the experiment is in the process of being evaluated. ${ }^{18}$ In 1997, Korea launched a pilot DRG program for inpatient care, covering nine disease categories (25 codes) which together accounted for $25 \%$ of inpatient cases. ${ }^{6}$ The pilot, which was voluntary, built in generous margins over FFS to overcome provider opposition. It also built in outlier payment features to reduce skimping. Some previously uncovered services were bundled in the DRGs, so that the DRG pilot in effect involved an expansion of insurance coverage. Comparing changes in reformed and unreformed hospitals, it has been estimated that DRGs led to a 14\% reduction in cost, a 6\% reduction in average length of stay, and a substitution towards outpatient care away from inpatient care. No adverse effects on quality were found. In 2001, the pilot program was extended to all hospitals for the same disease categories. Taiwan (China) has also taken steps to move away from FFS. ${ }^{11}$ A DRG system was phased in for the 50 most common diseases. Comparing changes between reformed and unreformed hospitals, studies for two of the covered procedures found that DRGs reduced both cost per case and length of stay, but increased volume, so much so that total payments in respect of the two procedures increased. ${ }^{29}$ Taiwan (China) is set to extend the use of DRGs in 2005, and is also experimenting with global budgets.

Singapore has also launched major supply-side reforms, notably in the corporatization of its hospital sector. ${ }^{25}$ By making hospitals more autonomous, it was envisaged that exposure to market forces would make them more responsive and efficient, and that they would improve quality faster than would otherwise be the case. Rather than corporatizing individual hospitals, the Singapore government created a single corporation, the Health Corporation of Singapore (HCS), under whose control around one quarter of Singapore's hospitals were placed, accounting for nearly half of Singapore's national bed stock. HCS, a holding company, is governed by private law, but is wholly owned by the government and answerable to the Ministry of Health. HCS can hire and fire staff, set terms of remuneration, and has considerable power to set prices. It is the residual claimant, but this is muted by the fact that although after-tax surpluses can be kept, the government continues to cover any deficit through a subsidy, albeit on the understanding the subsidy will diminish over time.

There does not appear to have been a rigorous evaluation of the impacts of Singapore's hospital corporatization program. Trends in various indicators for the corporatized hospitals have been reported for the period after corporatization ${ }^{25}$, but what would like to see is whether key outcomes changed differently before and after the reform between the corporatized and uncorporatized hospitals. Some points do, however, emerge. Cost recovery grew in the corporatized hospitals, from $15 \%$ of revenues before the reform to $55 \%$ in 2002 . This was achieved by raising prices. The government was forced, in the end, to impose limits on average charges per patient day. One newly corporatized hospital took the opportunity of the reform to 
eliminate C-class beds, whose (typically low-income) occupants receive similar medical care but have only basic hotel facilities and pay only $80 \%$ of the cost. The costs of these beds are met in part from profits earned on more expensive (B- and A-class) beds. Physician earnings increased in the corporatized hospitals, and in order to stem the brain drain from unreformed hospitals to reformed hospitals, the government was forced to allow unreformed hospitals to set their own fees as well. The reforms precipitated considerable upward pressure on doctors' salaries throughout the system, but especially on those of surgeons. Concerns have also been voiced about a reform-induced scramble to acquire the latest technology, and dumping of patients on the uncorporatized sector.

\section{Separating prescribing and dispensing}

As in China and several other developing countries is East Asia, doctors in Japan and the Tiger economies have traditionally both prescribed and dispensed drugs, and drug sales have traditionally been a major source of income for them. ${ }^{30}$ This is often argued to be a factor behind the high rates of drug use in these systems. In the OECD countries other than Japan and Korea, drug expenditures account for $16.8 \%$ of total health expenditures. In Japan the figure is $18.4 \%$, while in Korea the figure is $28.2 \%{ }^{1}$ The suspicion of over-use of drugs in such settings (a fact rather than merely a suspicion in the case of China ${ }^{31}$ ) led to moves in some systems to separate the functions of prescribing and dispensing. Korea introduced such a reform in 2000 against stiff opposition from physicians, who went on strike and secured substantial concessions, including a compensatory increase in medical fees (some rising by as much as $40 \%$ ). ${ }^{32}$ Taiwan (China) has started implementing a separation policy on an incremental basis, and has been the subject of a study that compares changes over time across reformed and unreformed providers. ${ }^{30^{*}}$

Several lessons emerge from Korea's and Taiwan (China)'s experiences with separating prescribing and dispensing. First, there is a risk that that compensation for those who lose out from the policy (doctors but potentially too pharmacists, who lose prescribing rights) is so generous it offsets any cost-savings from reduced over-consumption of drugs. In Taiwan (China), where consultation and dispensing fees were both raised (the latter were paid to pharmacists after the reform and to physicians before), it is estimated that while more 'rational' prescribing resulting from the separation did lead to cost-savings, they were absorbed entirely by the compensation costs. ${ }^{30}$ Second, there is a risk that health providers find ways-legal or notto continue to earn profits from dispensing. In Taiwan (China), clinics were allowed to hire onsite pharmacists, and unsurprisingly many did so-the share of clinics with on-site pharmacists jumped from zero to $60 \%$ following the separation policy. ${ }^{30}$ Since, these onsite pharmacists were paid a salary by the provider, the provider's incentives remain unchanged. Unsurprisingly, the separation policy had little or no impact on costs and prescribing behavior in clinics with onsite pharmacists. Even if the hiring of an onsite pharmacist is illegal, providers might be able to collude with dispensing pharmacists (some of whom may be former colleagues and friends) and channel patients to them; they may receive financial or in-kind 'tokens of gratitude' for their efforts. ${ }^{32}$ A third lesson is that providers may substitute diagnostic tests and examinations for drugs to maintain their incomes. ${ }^{30,32}$ In Taiwan (China), it does not seem they did so ${ }^{30}$, and there is no evidence on the issue for Korea. The final point worth making is that

\footnotetext{
* A suggestion along these lines in early 2005 from a journalist in Singapore led to an outcry from Singapore’s Medical Association http://www.sma.org.sg/sma_news/3701/hobbit.pdf.
} 
while the separation of prescribing and dispensing ensures the provider has no incentive to prescribe unnecessary drugs, it does not him a positive incentive to engage in cost-consciousness prescribing $^{32}$, as does a policy where doctors (rather than patients) have to pay for some or all of the costs of the drugs they prescribe out of their practice income. ${ }^{33,34}$

\section{Who uses health services and how much?}

How do the financing and delivery features of the systems play out in terms of utilization rates and inequalities in service use?

Factoring in use of traditional Chinese medicine (TCM) and other traditional providers, Japan and the Tigers have higher utilization rates of outpatient care than the OECD as a whole (Table 3). Hong Kong (China), for example, has almost twice as many general practitioner visits per year as the OECD as a whole. Inpatient care, by contrast, is less heavily used in Japan and the Tigers. This likely reflects the aforementioned extra services offered by ambulatory facilities in Japan and the Tiger economies.

What of inequalities in service use between the poor and better off? Outpatient visits in Korea and Taiwan (China) are pro-poor, but pro-rich in Hong Kong (China). This may reflect the reliance on out-of-pocket payments for outpatient care in Hong Kong (China), and the fact the population is covered by public insurance for ambulatory as well as inpatient care in Korea and Taiwan (China). In all three systems, inpatient care use is higher among the poor. It is least prorich in Korea, perhaps reflecting the fact that many services-including some high-tech services

and the specialist surcharge — are not covered by the UHI package. ${ }^{19,29}$ Comparing inequalities in the Tigers with inequalities in the OECD countries is not straightforward for ambulatory care, because of different definitions. Western doctor visits are less pro-poor in the Tiger economies than general practitioner (GP) visits are in the OECD, but are more pro-poor than specialist visits are there. In none of the three Tiger economies is inpatient care as pro-poor as it is in a typical OECD country. 
Table 3: Use of services and inequalities in service use by income*

\begin{tabular}{|c|c|c|c|c|c|c|c|c|c|c|}
\hline & \multicolumn{6}{|c|}{ Western doctors } & \multicolumn{2}{|c|}{$\begin{array}{c}\text { Traditional Chinese } \\
\text { medicine }\end{array}$} & \multicolumn{2}{|c|}{ Inpatient care } \\
\hline & All wes & doctors & General & titioners & Spe & & & & & \\
\hline & $\begin{array}{l}\text { Average } \\
\text { per capita }\end{array}$ & $\mathrm{CI}$ & $\begin{array}{c}\text { Average } \\
\text { per capita }\end{array}$ & $\mathrm{CI}$ & $\begin{array}{c}\text { Average } \\
\text { per capita }\end{array}$ & $\mathrm{CI}$ & $\begin{array}{c}\text { Average } \\
\text { per capita }\end{array}$ & $\mathrm{CI}$ & $\begin{array}{c}\text { No. per } 100 \\
\text { persons }\end{array}$ & $\mathrm{CI}$ \\
\hline $\begin{array}{l}\text { Hong Kong } \\
\text { (China) }\end{array}$ & 8.27 & 0.0241 & 6.99 & 0.0573 & 1.27 & -0.1580 & 2.55 & 0.0237 & 14.00 & -0.0954 \\
\hline Japan & 16.00 & & & & & & & & 9.57 & \\
\hline $\begin{array}{l}\text { Korea, Rep. } \\
\text { Singapore }\end{array}$ & 9.76 & -0.0234 & & & & & 1.38 & -0.0321 & $\begin{array}{c}7.00 \\
12.00\end{array}$ & -0.0734 \\
\hline Taiwan (China) & 8.44 & -0.0534 & & & & & 2.02 & 0.0401 & 10.00 & -0.1470 \\
\hline OECD average & 7.15 & & 3.62 & -0.0904 & 1.62 & 0.0105 & & & 16.40 & -0.1516 \\
\hline
\end{tabular}

* Data are from Lu et al. ${ }^{35}$, except in the case of Japan and Singapore, where the numbers are from Imai ${ }^{18}$ and the World Bank's World Development Indicators respectively, and the OECD averages, which were computed from the OECD's Health Statistics database in the cases of Western doctor visits and inpatient admissions, and Masseria and van Doorslaer ${ }^{36}$ in the case of GP and specialist visits. OECD averages are based on 15-19 countries, depending on the variable. Figures for Hong Kong (China) refer to 2002, Japan's and Korea's to 1998, Singapore's to 1994, and those for Taiwan (China) to 2001. Japan's figure for Western physician consultations may include visits to traditional providers. The concentration index measures the extent to which use is higher among higher income groups: a positive value indicates that, on average, the better off make greater use of services; a negative index indicates the opposite. ${ }^{37}$ The OECD concentration indices are from Masseria and van Doorslaer. 


\section{CONCLUSIONS}

The differing health systems and reform experiences of Japan and the Asian Tigers provide many learning opportunities for developing countries, especially those in East Asia who face similar challenges today to those faced by Japan and the Tigers during the latter part of the $20^{\text {th }}$ century.

In none of the five systems examined is there any compelling evidence of excessive or runaway health expenditures. Indeed, the only serious outlier internationally is Singapore which spends barely half of the share of GDP one would expect of a country with its per capita income. This is despite the fact the five systems span the full spread of financing systems, ranging from the tax-financed system in Hong Kong (China), through the social insurance systems of Japan, Korea and Taiwan (China), to Singapore's largely privately financed system. One lesson, then, seems to be that all types of financing system can be adapted to keep health spending in checkthere is no right or wrong financing mix from the point of view of macroeconomic expenditure control.

Another lesson that emerges in respect of financing is the limited role in practice of medical savings accounts. Despite the enthusiasm for them in some quarters, one cannot help but be struck by the fact that they have never accounted for more than $10 \%$ of total spending in Singapore. Even more striking is the fact that the complementary insurance and safety net schemes (Medishield and Medifund) have played an even smaller role, accounting for just 2\% of total spending together. Singapore's system is more accurately classified as a largely out-ofpocket system with limited tax subsidies.

In terms of who bears the burden of health financing, Japan and the Tigers offer similar general messages to the OECD countries, but provide some useful pointers with respect to specifics. The progressivity estimates reviewed above point, as in the OECD countries, to taxfinanced systems being the most progressive, and social insurance systems being somewhat regressive or close to proportional. Beyond that, the lesson that emerges is that the precise degree of progressivity of each source of finance depends on the design features of the system-the emphasis on direct versus indirect taxes, the degree to which luxury goods are taxed at a higher rate, the height of any ceilings on social insurance contributions, whether the poor are exempt from social insurance contributions, the fraction of health spending covered by the benefit package, the extent to which the poor face reduced copayments, and so on. Likewise the degree to which households, especially poor ones, suffer from catastrophic payments also depends on system features-whether there are caps on copayments, how large they are, and whether they are lower for the poor. In terms of who bears the burden of health finance, therefore, just as much may hinge on the design features of each source as on the mix between them.

On the delivery side, too, Japan and the Tigers offer some interesting lessons. While all rely predominantly on the private sector for the delivery of ambulatory care, some opt for the public sector to deliver hospital care while others favor the private sector. Singapore provides some evidence on the consequences of making public hospitals more private without actually 
privatizing them. Unfortunately, hard evidence on the impacts of Singapore's hospital corporatization initiative is not available, but the (sometimes anecdotal and selective) evidence that does exist points to a number of (largely predictable and mostly negative) consequences, including rapid increases in costs and prices charged to patients, rapid growth in technology and high-tech interventions (especially surgical procedures), and attempts by hospitals to dump highcost patients and to avoid offering services to low-income patients.

Japan and the other Tigers also offer some useful lessons on paying providers. Korea's experience with a narrow benefit package provides an illustration of the danger of providers shifting demand from insured services whose prices are regulated to uninsured services whose prices are unregulated and highly lucrative. The social insurance systems also offer some useful lessons vis-à-vis reimbursement of insured services. The experiences of Korea and Taiwan (China) are less positive than that of Japan, which has managed to combine careful cost control with fine-tuning of profit margins on different types of care. Experiences with DRGs in Korea and Taiwan (China) have also proved useful, both pointing towards cost-savings, but in the case of Taiwan (China) drawing attention to the possible knock-on effects on service volume and total health spending. Korea and Taiwan (China) both offer important lessons for the separation of prescribing and dispensing. For example, compensation costs in both cases were substantial and in the case of Taiwan (China) were so large they offset the cost savings caused by more 'rational' prescribing. The risk of cost-savings never being realized because of other concessions to providers — such as allowing them to have onsite pharmacists-is also illustrated by the pilot in Taiwan (China).

It would be a mistake to view the health systems of Japan and the Tigers as 'finished business' - all are likely to carry on exploring ways of financing and delivering health care more

efficiently, if not also more equitably. But in the meantime, their existing arrangements and recent reform experiences all provide potentially useful lessons for East Asia's developing countries, if not for one another.

\section{References}

1. OECD Health Data [program]. Paris: OECD, 2005.

2. World Health Organization. World Health Report 2005: Make every mother and child count. Geneva: World Health Organization, 2005.

3. Lu J-FR. The Application of National Health Account Approaches in Estimating National Health Expenditures: Taiwan (China) Experience. Tao-Yuan: Department of Health Care Management, Chang Gung University, 2001.

4. O'Donnell O, Van Doorslaer E, Rannan-Eliya R, et al. Who pays for health care in Asia? EQUITAP Working Paper \# 1, Erasmus University, Rotterdam and IPS, Colombo, 2005.

5. Lu JR, Hsiao WC. Does Universal Insurance Make Health Care Unaffordable? Lessons from Taiwan (China). Health Affairs 2003;22(3 (May/June 2003)):77-88. 
6. Kwon S. Payment system reform for health care providers in Korea. Health Policy Plan 2003;18(1):84-92.

7. Liu E, Yue S. Health care expenditure and financing in Singapore. Hong Kong (China): Research and Library Services Division, Hong Kong (China) Legislative Council Secretariat, 1999.

8. Hanvoravongchai P. Medical Savings Accounts: Lessons Learned from Limited International Experience. Geneva: WHO, 2002.

9. Lim MK. Shifting the burden of health care finance: a case study of public-private partnership in Singapore. Health Policy 2004;69(1):83-92.

10. Nichols L, Prescott N, Phua K. Medical savings accounts for developing countries. In: Schieber G, ed. Innovations in Health Care Financing. Washington DC: World Bank, 1997.

11. Lu JFR. Social health insurance experience in Taiwan (China), 2005.

12. Kakwani NC. Measurement of tax progressivity: An international comparison. Economic Journal 1977;87(345):71-80.

13. Wagstaff A, van Doorslaer E, Calonge S, et al. Equity in the finance of health care: some international comparisons. J Health Econ 1992;11(4):361-87.

14. Wagstaff A, van Doorslaer E, van der Burg H, et al. Equity in the finance of health care: some further international comparisons. J Health Econ 1999;18(3):263-90.

15. Kwon S. Health care financing reform and the new single payer system in the Republic of Korea: social solidarity or efficiency? International Social Security Review 2003;56(1):75-94.

16. Ikegami N, Campbell JC. Medical care in Japan. N Engl J Med 1995;333(19):1295-9.

17. Ikegami N, Campbell JC. Health care reform in Japan: the virtues of muddling through. Health Aff (Millwood) 1999;18(3):56-75.

18. Imai Y. Health care reform in Japan: OECD, 2002.

19. Kwon S. Billing of medical services and the financial burden of patients in Korea, 2005. 
20. Wagstaff A, Van Doorslaer E. Progressivity, horizontal equity and reranking in health care finance: a decomposition analysis for The Netherlands. Journal of Health Economics 1997;16:499-516.

21. Wagstaff A, van Doorslaer E. Catastrophe and impoverishment in paying for health care: with applications to Vietnam 1993-98. Health Econ 2003;12(11).

22. Xu K, Evans DB, Kawabata K, Zeramdini R, Klavus J, Murray CJ. Household catastrophic health expenditure: a multicountry analysis. Lancet 2003;362(9378):111-7.

23. Van Doorslaer E, O'Donnell O, Rannan-Eliya RP, et al. Paying out-of-pocket for health care in Asia: Catastrophic and poverty impact. EQUITAP Working Paper \#2, Erasmus University, Rotterdam and IPS, Colombo, 2005.

24. Chou S-Y, Liu J-T, Hammitt JK. National Health Insurance and Precautionary Saving: Evidence from Taiwan (China). Journal of Public Economics 2003;87(9-10):1873-94.

25. Phua KH. Attacking Hospital Performance on Two Fronts: Network Corporatization and Financing Reforms in Singapore. In: Preker AS, Harding A, eds. Innovations in Health Service Delivery: The Corporatization of Public Hospitals. Washington DC: World Bank, 2003.

26. Rannan-Eliya RP. Status of National Health Accounts in Asia-Pacific Region: Results of the APNHAN Survey 2001. Colombo: Health Policy Programme, Institute of Policy Studies, Sri Lanka, 2001.

27. Lim MK. Health care systems in transition. II. Singapore, Part I. An overview of health care systems in Singapore. J Public Health Med 1998;20(1):16-22.

28. Leung GM, Wong IO, Chan WS, Choi S, Lo SV. The ecology of health care in Hong Kong (China). Soc Sci Med 2005;61(3):577-90.

29. Eggleston K, Hsieh C. Health Care Payment Incentives in East Asia: Taiwan (China), South Korea and the PRC in Comparative Perspective. Applied Health Economics and Health Policy in press.

30. Chou YJ, Yip WC, Lee CH, Huang N, Sun YP, Chang HJ. Impact of separating drug prescribing and dispensing on provider behaviour: Taiwan (China)'s experience. Health Policy and Planning 2003;18(3):316-29.

31. Zhang X, Feng Z, Zhang L. Analysis on Quality of Prescription of Township Hospitals in Poor Areas. Journal of Rural Health Service Management 2003;23(12):33-35. 
32. Kwon S. Pharmaceutical reform and physician strikes in Korea: separation of drug prescribing and dispensing. Soc Sci Med 2003;57(3):529-38.

33. Stewart-Brown S, Surender R, Bradlow J, Coulter A, Doll H. The effects of fundholding in general practice on prescribing habits three years after introduction of the scheme. Bmj 1995;311(7019):1543-7.

34. Maynard A, Bloor K. Dilemmas in regulation of the market for pharmaceuticals. Health Aff (Millwood) 2003;22(3):31-41.

35. Lu J-fR, Leung GM, Kwon S, Tin KY, Van Doorslaer E, O'Donnell O. Horizontal equity in health care utilization: evidence from three high-income Asian economies, 2005.

36. Masseria C, van Doorslaer E. Income-Related Inequality in the Use of Medical Care in 21 OECD Countries. Paris: OECD, 2004.

37. Wagstaff A, van Doorslaer E, Paci P. Equity in the finance and delivery of health care: Some tentative cross-country comparisons. Oxford Review of Economic Policy 1989;5:89-112. 